\title{
EFFECTS OF HEALTH-SEEKING BEHAVIOR ON COMPLIANCE OF LONG-TERM TREATMENT AMONG GLAUCOMA PATIENTS
}

\author{
MIDHET NASIM ${ }^{1}$, AMIR ZEB ${ }^{2}$, SAMRIN KHAN ${ }^{3}$
}

${ }^{1}$ Low vision Specialist/ Public Health Evaluation Coordinator, AAN Associates, Pakistan. ${ }^{2}$ Senior Optometrist, EDO hospital, Wah Cantt Pakistan. ${ }^{3}$ Public Health (Clinical) specialist, Hanadi clinic, Sanaaya Area, Al-ain, Abu Dhabi. Email: amirzebjadoon@gmail.com

Received: 31 August 2021, Revised and Accepted: 07 October 2021

\section{ABSTRACT}

Objectives: The objectives of the study were to determine the level of non-compliance with long-term glaucoma therapy in patients presenting in glaucoma department of Al-Shifa Trust Eye Hospital and to identify the health-seeking predictors affecting it.

Methods: A cross-sectional study of 5 months was conducted on glaucoma patients who are taking follow-up visits in glaucoma department for 6 months or more. The level of compliance with glaucoma medication (dependent variable) was assessed through a scale at first and further transformed into binary variable afterward. Chi-square test of independence was used followed by logistic regression to find out the predictors of compliance.

Results: A total of 200 patients participated in the study. Majority of them were from urban background ( $\mathrm{n}=125,62.5 \%$ ) and were diagnosed with glaucoma 1-5 years ( $\mathrm{n}=104,52 \%)$ back. Almost $16.00 \%$ of patients were not giving follow-up on given appointment. Moreover, $10.00 \%$ were not taking proper medications and prescribed dosage of medications was not taken by $21.5 \%$. Intraocular pressure was higher than normal limits in $13.00 \%$. Self-medication $\left(\chi^{2}(\mathrm{df})=5.44(1), 0.01,0 \mathrm{R}=0.28(0.09-0.81)\right.$ and doctor-patient communication $\left(\chi^{2}(\mathrm{df})=18.25(1), 0.03,0 \mathrm{R}=2.27(1.06-4.86)\right.$ were significant health-seeking predictors of glaucoma treatment compliance.

Conclusion: Blindness due to glaucoma is an avoidable condition if underlying factors such as self-medication is discouraged and doctor-patient communication can be improved in the glaucoma department.

Keywords: Adherence, Socioeconomic determinants, Self-medication, Doctor-patient communication.

(C) 2021 The Authors. Published by Innovare Academic Sciences Pvt Ltd. This is an open access article under the CC BY license (http://creativecommons. org/licenses/by/4.0/) DOI: http://dx.doi.org/10.22159/ijms.2021v9i6.43024. Journal homepage: https://innovareacademics.in/journals/index.php/ijms

\section{INTRODUCTION}

Glaucoma is a condition in which unilateral or bilateral progressive optic neuropathy which is associated with visual field loss and may or may not be associated with raised intraocular pressure (IOP). Glaucoma is the second leading cause of blindness worldwide [1].

Globally, the prevalence of glaucoma is 64.3 million, which is expected to rise to 11.8 million by 2040 . Africa and Asia are the two continents with the highest burden of glaucoma [2]. According to the World Health Organization, 5.2 million people are blind in the world due to glaucoma that makes up a total of $15 \%$ of the world's blindness [3].

In South Asia, total glaucoma prevalence in 2013 was 3.54\%. From 2013 to 2040, South Asia is expected to record the steepest increase in the number of glaucoma cases as compared to other regions $(17.06$ million to 32.90 million) [4].

Glaucoma is the $4^{\text {th }}$ leading cause of blindness in Pakistan with the prevalence of $7.10 \%$ after cataract $(66.00 \%)$, corneal opacity $(12.60 \%)$ and refractive error (11.40\%). There are more than 1.80 million glaucoma patients in Pakistan and almost half of them have lost their eyesight, due to delay in diagnosis and treatment [5]. Almost one million glaucoma patients were blind due to lack of awareness and expensive treatment in Pakistan [6].

Compliance in medical terms is defined as the act of following the recommendations of one's medical practitioner [7]. The aim of glaucoma treatment revolves around maintaining the IOP to prevent optic nerve damage and loss of vision [8]. Medical compliance among glaucoma patients is poor and about $20 \%$ to $66 \%$ of them do not use their medication as directed [9].
Different studies have shown that there is high non-compliance with glaucoma therapy and different factors had been associated with noncompliance in different areas of the world [10-13]. The most common reasons reported for non-compliance was asymptomatic nature of the disease [14] along with the factor of negligence [15]. The monthly income, the total expenditure towards the treatment, time required for one hospital visit including travel, stay, and loss of wages were also identified as determinants of compliance [16]. In addition, important component of health-care utilization is the health-seeking behavior (HSB). Needs factors such as physicians and patients view are the important mediator of HSB [17]

There is lack of comprehensive data in Pakistan regarding compliance to glaucoma treatment as well as there is no valid information that highlights the root causes of non-compliance with long-term glaucoma therapy with special consideration to health-seeking behavior. Treatment of glaucoma is incomplete without good patient compliance and adherence to the prescribed schedule. Adherence to treatment is now considered as an essential component of the glaucoma treatment as only a little carelessness can reverse the process and lead the patient to vision-threatening condition. Compliance can be made better if sufficient good quality data for the root causes of non-compliance are known. The objectives of the study were to determine the level of non-compliance with long-term glaucoma therapy in patients presenting in glaucoma department of Al-Shifa Trust Eye Hospital (ASTEH) and to identify the health-seeking predictors affecting it.

\section{METHODS}

A cross-sectional study was carried to assess the level of compliance as well as predictors of non-compliance in patients of long-term glaucoma therapy at the Glaucoma department, ASTEH, Rawalpindi, Pakistan. 
ASTEH is situated in Rawalpindi, one of the top five metropolitan cities of Pakistan [18]. The purpose of doing this study in this setting is based on the fact that this hospital is not only fully equipped with all the modern investigative facilities but also caters a large proportion of glaucoma confirmed and glaucoma suspect cases each year from every socioeconomic background.

All patients of glaucoma department were included in the study. Data were collected directly from patients over the duration of 5 months, starting from October 2018 to February 2019

Non-probability consecutive sampling technique was adopted for data collection. All those patients who visiting glaucoma department for consultation during the study duration with follow-up visits of minimum 6 months (as an indicator of long-term therapy) and aged 20 years and above were inducted. Patients who were presenting with other ocular comorbidities and those who have undergone recent glaucoma surgeries ( $<1$ year) were excluded from the study.

The sample size was 196 but it was extended to 200 patients to overcome the chance of non-response rate. It was calculated by the means of OPEN-EPI software [19]. Prevalence of glaucoma was taken to be $15 \%$ based on the data of the WHO and was entered in the software at a confidence interval of $95 \%$ to calculate the sample size. The formula used for sample size calculation was:

Sample size $n=[\operatorname{DEFF} * \mathrm{~Np}(1-\mathrm{p})] /\left[\left(\mathrm{d}^{2} / \mathrm{Z}_{1-\alpha / 2}^{2} *(\mathrm{~N}-1)+\mathrm{p}^{*}(1-\mathrm{p})\right]\right.$

Data was collected by principal author using structured, interviewbased questionnaire which was translated in the Urdu language for better comprehension of participants. The dependent variable of this study was compliance with long-term glaucoma therapy. Compliance was assessed by four indicators, based on previous literature [19]. It included proper follow-up on given time, comparison between the medications prescribed and used, comparison between the prescribed and used dosage, and IOP checked on the day of examination under the supervision of ophthalmologist (Table 1).

Independent variables were divided into five sections: the first section consisted of patient's basic information and included six questions. This was followed by a section of Socio-Economic questions (8). The third section had seven questions on ocular and medical history of the patient. The second last section had four questions on patient's basic knowledge and understanding of disease and treatment regimen. The last section consisted of questions on patient's overall satisfaction and family support (7). Of all these variables, five were taken as indicators of HSB for finding predictors of non-compliance based on previous literature $[17,20-23]$.

The study was conducted after approval was taken from the Ethical Review Committee of Pakistan Institute of Ophthalmology. The collected data was entered on a daily basis in the statistical package for social sciences version 20. Data analysis was done in two phases; descriptive analysis followed by inferential statistics. Descriptive statistics were generated for all independent variables. Categorical data were presented in the form of frequencies and percentages. Valid percentages were reported in variables with missing data.

Chi-square test for independence variables was used for finding an association between outcome variable and independent variable. A significance level of $5 \%$ was used for all inferential statistics. The variables achieving statistical significance in univariate analysis were

Table 1: Category of compliance

\begin{tabular}{lll}
\hline Level of compliance & Condition & Scale \\
\hline Patient compliant & $\begin{array}{l}\text { Fulfilling all the four } \\
\text { indicators }\end{array}$ & 4 \\
Patient non-compliant & $\begin{array}{l}\text { Not fulfilling any one } \\
\text { indicator }\end{array}$ & $1,2,3$ \\
\hline
\end{tabular}

included in multivariate logistic regression analysis to identify the possible predictors of the outcome variable.

\section{RESULTS}

\section{Background information}

Majority of the cases had been suffering from glaucoma for $<5$ years $(104,52.00 \%)$ and 16 of the cases $(8.00 \%)$ had glaucoma for more than 15 years. All the 200 respondents who participated in the study were age 20 years or above, and most of them were $<50$ years $(n=106,53.00 \%)$. Gender distribution demonstrated that males were predominant in the sample $(\mathrm{n}=114,57.00 \%)$ as compared to females. Around one-fourth ( $n=53,26.50 \%)$ of the respondents were illiterate, followed by $45(22.50 \%)$ with only primary education. Among all the respondents, $48(24.00 \%)$ were unmarried. Most of the respondents were from urban background $(n=125,62.50 \%)$ (Table 2).

Half $(n=100,50.00 \%)$ of the respondents were dependent on their family members for fulfilling their basic needs and almost same number $(n=98,49.00 \%)$ of respondents were sole earners of their whole family. Forty percent of the working lot had private jobs $(n=80)$ and low family income $(<30 \mathrm{k})$ reported by almost two-third $(\mathrm{n}=123$, $61.50 \%$ ) of participants.

Almost half of the participants do not consider their glaucoma treatment as affordable $(n=86,43.00 \%)$. This was because of the indirect expenses as large proportion $(n=171,85.50 \%)$ of glaucoma patients used a public transport as a mode to reach the health facility for treatment and $177(88.50 \%)$ of the total cases reported that the expense of one visit to hospital was ranging from USD 6-12. Moreover, $42.00 \%(n=84)$ respondents said that the single time purchase of their medications is between USD 7-12 (Table 3).

Glaucoma is affecting greater number of females $(n=14,53.80 \%)$ as compared to their counterparts for 11-15 years. Bargraph of both genders in relation with duration of glaucoma are shown in Fig. 1.

As far as ocular and medical history is concerned, 130 respondents (65.00\%) came for examination because of their scheduled appointment, followed by $70(35.00 \%)$ with other complaints that are given in Table 4. One-fourth of the participants had not undergone any

Table 2: Participant's information

\begin{tabular}{lll}
\hline Variable & $\mathbf{n}$ & $\mathbf{\%}$ \\
\hline Age (years) & & \\
$20-50$ & 106 & 53.00 \\
$>50$ & 94 & 47.00 \\
Duration of glaucoma & & \\
(years) & & 52.00 \\
$1-5$ & 104 & 27.00 \\
$6-10$ & 54 & 13.00 \\
$11-15$ & 26 & 8.00 \\
$16-20$ & 16 & 26.50 \\
Education & & 22.50 \\
Illiterate & 53 & 35.50 \\
Primary & 45 & 15.50 \\
Secondary & 71 & 57.00 \\
Higher & 31 & 43.00 \\
Gender & & \\
Male & 114 & 37.50 \\
Female & 86 & 62.50 \\
Locality & & \\
Rural & 75 & 2.00 \\
Urban & 125 & 64.00 \\
Marital status & & 24.00 \\
Divorced & 4 & \\
Married & 128 & \\
Unmarried & 48 & \\
Widow/Widower & 20 & \\
\hline$\quad$
\end{tabular}


ocular surgical procedure $(n=55,27.50 \%)$ and twenty-six $(13.00 \%)$ respondents had a positive history of ocular trauma

Almost half (n=89, 44.50\%) respondents accepted self-medication (traditional methods) as their first treatment choice for glaucomarelated ocular issues, before diagnosis. Eight (4.00\%) glaucoma patients said that they do not know if anyone had glaucoma in their family previously. A total of 115 (57.50\%) glaucoma patients were comorbid with 73 (36.50\%) reporting hypertensive and $42(21.00 \%)$ of them reporting being diabetic.

Total compliance of the patients was extracted based on following four variables. Around $1 / 4^{\text {th }}$ of the patients responded that they do not take proper dosage of the medication on prescribed time $(n=43,21.50 \%)$ Thirteen percent $(n=26)$ were not having IOP in the normal range when checked at the time of data collection. Almost $10 \%(n=19)$ patients were not even using the prescribed medications and 31 (15.50\%) were not taking follow up on the given appointment (Table 5).

The composite outcome for above variables represented the level of compliance with glaucoma therapy and is shown in the Fig. 2.

More than $15 \%(n=35,17.50 \%)$ of the respondents were not aware of the cause for their vision loss. More than half of respondents $(n=109$, $54.50 \%$ ) reported that their eye medication do not fully control the disease. In addition, 40 (20.00\%) respondents said that they had confusion regarding schedule of prescribed medications with $24(60.00 \%)$ reported the high (more than one) number of medicines per dose to be the cause for confusion (Table 6)

Seventy-three (36.50\%) patients were not satisfied with their doctor-patient communication and same percentage of patients reported ocular side effects with the treatment regimen that they were currently using. More than $20 \%(n=45,22.50 \%)$ of the participants reported that they spent $4-6 \mathrm{~h}$ on a single visit to the hospital. Patients also said that they face difficulty in instilling drops to their eyes $(n=30$, $15.00 \%)$ with only $83(41.50 \%)$ visiting the hospital in the presence of helper/attendant.

Patients found no benefit of the treatment to their vision or their disease status $(n=76,38.00 \%)$. Nearly same frequency $(n=77,38.50 \%)$ of patients said that they are not satisfied with the treatment (Table 7).

\section{Association of HSB related variables with outcome}

Chi-square test of independence was carried out to check association of compliance with independent variables. Out of total 159 patients who had never used self-medication(traditional methods) as first treatment choice for glaucoma-related ocular issue, $32.07 \%$ were non-compliant with glaucoma treatment. Pearson chi-square $\left(\chi^{2}[\mathrm{df}]=5.44 \quad[1]\right.$, $\mathrm{p}=0.020$ ) showed that there was a significant association between level of compliance and practice of self-medication.

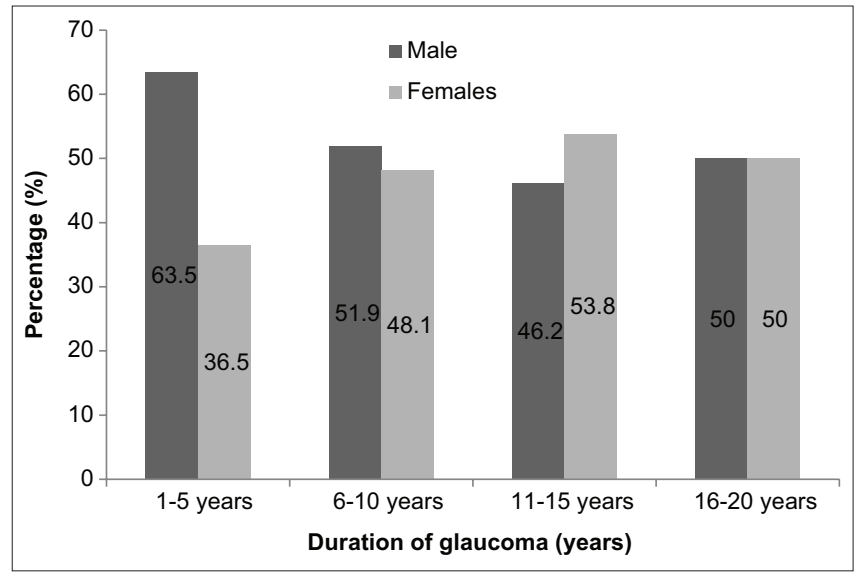

Fig. 1: Duration of glaucoma with gender
Patient satisfaction played a major role in increasing compliance of the patient to treatment regimen. Patients $(n=127)$ who agreed that their doctor informed them everything about the treatment and prognosis of their condition were found more compliant $(n=105,82.70 \%)$ as compared to their un-agreeing counterparts $(\mathrm{p}<0.050)$. Similarly, overall satisfaction, perceived benefit, and knowledge about eye drops also showed a significant association (Table 8).

\section{Predictors of compliance to glaucoma treatment}

In multivariate analysis, the multiple regression model was constructed by utilizing all the five variables of health-seeking behavior as they all were found statistically significant during univariate analysis. The overall model explained $18.90 \%$ (Cox \& Snell $\mathrm{R}^{2}=0.189$ ) to $27.30 \%$ (Nagelkerke $\mathrm{R}^{2}=0.273$ ) of the variation in outcome variable and was statistically significant $\left(\chi^{2}(d f)=41.97(5), p=0.010\right)$. It was observed that patients who did self-medication has 0.28 times $(p=0.01,0.09-0.81)$ less compliance as compared to those who didn't. Information about the treatment regimen by physician was also a statistically significant predictor of glaucoma compliance, as individuals who had good awareness about the treatment duration and their prognosis were 2.27 times $(p=0.030)$ more likely to be compliant with the glaucoma therapy than their less knowledgeable fellows. Satisfaction with the glaucoma treatment, perceived benefit of the treatment, and knowledge about the glaucoma medication were not observed to be statistically

Table 3: Socio-economic status of the respondents

\begin{tabular}{|c|c|c|}
\hline \multirow[t]{2}{*}{ Socio-economic status } & \multicolumn{2}{|c|}{ Descriptive } \\
\hline & $\mathbf{n}$ & $\%$ \\
\hline \multicolumn{3}{|l|}{$\begin{array}{l}\text { Earning members of } \\
\text { family }\end{array}$} \\
\hline Sole earner & 98 & 49.00 \\
\hline 2 members & 70 & 35.00 \\
\hline 3 members & 32 & 16.00 \\
\hline \multicolumn{3}{|l|}{ Cost of medication } \\
\hline USD 2-6 & 116 & 58.00 \\
\hline USD 7-12 & 84 & 42.00 \\
\hline \multicolumn{3}{|l|}{ Transport to hospital } \\
\hline Personal transport & 23 & 11.50 \\
\hline Public transport & 171 & 85.50 \\
\hline Private transport & 6 & 3.00 \\
\hline \multicolumn{3}{|l|}{ Expense of one visit } \\
\hline USD 6-12 & 177 & 88.50 \\
\hline USD $>12$ & 23 & 11.50 \\
\hline \multicolumn{3}{|l|}{ Affordability of treatment } \\
\hline Affordable & 84 & 42.00 \\
\hline Not affordable & 86 & 43.00 \\
\hline Somehow affordable & 30 & 15.00 \\
\hline \multicolumn{3}{|l|}{ Patient's working status } \\
\hline Dependent & 100 & 50.00 \\
\hline Non-dependent & 100 & 50.00 \\
\hline \multicolumn{3}{|l|}{ Job status } \\
\hline Government & 38 & 19.00 \\
\hline Private & 80 & 40.00 \\
\hline Others & 82 & 41.00 \\
\hline \multicolumn{3}{|l|}{ Family income } \\
\hline Low income $(<30 \mathrm{~K})$ & 123 & 61.50 \\
\hline High income $(>30 \mathrm{~K})$ & 77 & 38.50 \\
\hline
\end{tabular}

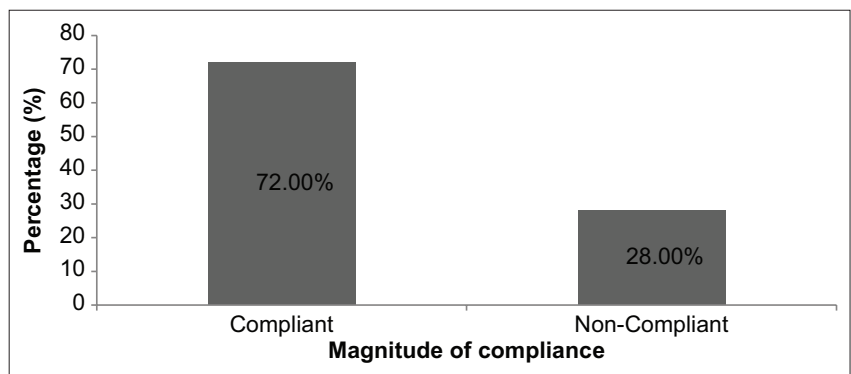

Fig. 2: Percentage of compliance in patients 
significant in final multivariate analysis. Detailed information regarding the multivariate analysis is available in Table 9.

\section{DISCUSSION}

The main objectives of the study were to determine the level of noncompliance in long-term glaucoma therapy and associated predictors in patients visiting tertiary eye care hospital.

There were two major predictors of non-compliance in the current study. The first is doctor-patient communication. It includes the information provided to the patient by their physician about the duration and schedule of treatment regimen. The study has shown that patients who were well-aware and properly guided by their doctor were 2.27 times $(p=0.030)$ more likely to be compliant as compared to the ones who were not well informed by their physicians. Alan and Robert stated that proper glaucoma management demands patients' adherence to therapy and is more likely to happen when the treatment regimen is simplified and well translated to the patient [24]. Similarly, Rubin Spann also said that poor communication between doctor and patient is a reason for patient's non-compliance to treatment plan [25]. Similar findings were reported by Taylor et al. in a qualitative study where patients

\section{Table 4: Frequency of ocular and medical history}

\begin{tabular}{|c|c|c|}
\hline Variable & $\mathbf{n}$ & $\%$ \\
\hline \multicolumn{3}{|c|}{ Reason for visiting } \\
\hline \multicolumn{3}{|c|}{ hospital } \\
\hline Blur vision & 22 & 11.00 \\
\hline Follow-up & 130 & 65.00 \\
\hline Pain & 32 & 16.00 \\
\hline Watering & 16 & 8.00 \\
\hline \multicolumn{3}{|c|}{ History of ocular surgery } \\
\hline No & 55 & 27.50 \\
\hline Yes & 145 & 72.50 \\
\hline \multicolumn{3}{|c|}{ History of ocular trauma } \\
\hline No & 174 & 87.00 \\
\hline Yes & 26 & 13.00 \\
\hline \multicolumn{3}{|l|}{ Self-medication } \\
\hline No & 111 & 55.50 \\
\hline Yes & 89 & 44.50 \\
\hline \multicolumn{3}{|c|}{$\begin{array}{l}\text { Family history of } \\
\text { glaucoma }\end{array}$} \\
\hline No & 141 & 70.50 \\
\hline Don't Know & 8 & 4.00 \\
\hline Yes & 51 & 25.50 \\
\hline \multicolumn{3}{|c|}{ History of hypertension } \\
\hline No & 116 & 58.00 \\
\hline Don't Know & 11 & 5.50 \\
\hline Yes & 73 & 36.50 \\
\hline \multicolumn{3}{|c|}{ History of diabetes } \\
\hline No & 149 & 74.50 \\
\hline Don't Know & 9 & 4.50 \\
\hline Yes & 42 & 21.00 \\
\hline
\end{tabular}

Table 5: Composite outcome variable (compliance)

\begin{tabular}{ll}
\hline Variables & $\mathbf{n}(\mathbf{\%})$ \\
\hline Follow up on time & $169(84.50)$ \\
Yes & $31(15.50)$ \\
No & \\
Proper medication & $181(90.50)$ \\
Yes & $19(9.50)$ \\
No & \\
Proper dosage & $144(72.00)$ \\
Yes & $56(28.00)$ \\
No & \\
Normal IOP & $174(87.00)$ \\
Yes & $26(13.00)$ \\
No & \\
\hline
\end{tabular}

reported good communication with their physicians as a triggering factor for taking glaucoma seriously and the following treatment properly [26]. Many other studies are also in agreement with the current study in stating that explanation of treatment by the doctor can positively affect the compliance of treatment [27-31].

Almost 30\% were found to be non-compliant with the long-term glaucoma therapy. This is alarming as it shows that one in every three person is non-compliant to treatment. This is in agreement with de Castro et al. review in which the non-compliance of long-term glaucoma therapy ranged between $4.60 \%$ up to $59.00 \%$ [32]. The study by Abu Hussein et al. showed more non-compliance (53.60\%) than the current study in an Egyptian population [11].

Twenty-one percent of patients $(n=43)$ were not following proper schedule of their prescribed regiment and almost same percentage $(20.10 \%)$ of respondents said that they have confusion regarding schedule of medication. Most of the patients $(65.00 \%)$ said that the reason for confusion was handling of multiple medications per day which is in agreement to Cook et al. where greater doses per day were the strongest predictor for non-adherence to glaucoma

Table 6: Knowledge and understanding about treatment

\begin{tabular}{lll}
\hline Variable & $\mathbf{n}$ & $\mathbf{\%}$ \\
\hline Knowledge about disease & & \\
$\quad$ No & 35 & 17.50 \\
$\quad$ Yes & 165 & 82.50 \\
Knowledge about eye drops & 109 & 54.50 \\
$\quad$ No & 91 & 45.50 \\
$\quad$ Yes & 160 & \\
Confusion about prescription & 40 & 20.00 \\
$\quad$ No & & \\
$\quad$ Yes & 11 & 27.50 \\
If yes, what is the reason of confusion & 24 & 60.00 \\
Inability to read prescription & 05 & 12.50 \\
$\quad$ Due to more than one medicines & & \\
$\quad$ Others &
\end{tabular}

Table 7: Patient satisfaction and family support

\begin{tabular}{|c|c|c|}
\hline Variable & $\mathbf{n}$ & $\%$ \\
\hline \multicolumn{3}{|c|}{ Doctor-patient communication } \\
\hline No & 73 & 36.50 \\
\hline Yes & 127 & 63.50 \\
\hline \multicolumn{3}{|c|}{ Side effects of treatment } \\
\hline No & 127 & 63.50 \\
\hline Yes & 73 & 36.50 \\
\hline \multicolumn{3}{|c|}{ Reported side effects } \\
\hline Burning & 22 & 11.00 \\
\hline Itching & 20 & 10.00 \\
\hline Stinging & 31 & 15.50 \\
\hline \multicolumn{3}{|c|}{ Time spent/visit (h) } \\
\hline $1-2$ & 34 & 17.00 \\
\hline$>2-4$ & 121 & 60.50 \\
\hline$>4-6$ & 45 & 22.50 \\
\hline \multicolumn{3}{|c|}{ Perceived benefit of treatment } \\
\hline No & 76 & 38.00 \\
\hline Yes & 124 & 62.00 \\
\hline \multicolumn{3}{|c|}{$\begin{array}{l}\text { Overall satisfaction with } \\
\text { treatment }\end{array}$} \\
\hline No & 77 & 38.50 \\
\hline Yes & 123 & 61.50 \\
\hline \multicolumn{3}{|c|}{ Problem instilling drops } \\
\hline No & 170 & 85.00 \\
\hline Yes & 30 & 15.00 \\
\hline \multicolumn{3}{|c|}{ Presence of helper/attendant } \\
\hline No & 117 & 58.50 \\
\hline Yes & 83 & 41.50 \\
\hline
\end{tabular}


Table 8: Determinants of compliance with treatment

\begin{tabular}{|c|c|c|c|c|c|}
\hline \multirow[t]{2}{*}{ Determinants } & \multicolumn{2}{|c|}{ Compliance } & \multirow[t]{2}{*}{$\chi 2$ (df) } & \multirow[t]{2}{*}{ p-value } & \multirow[t]{2}{*}{ Phi } \\
\hline & Yes n (\%) & No n (\%) & & & \\
\hline \multicolumn{6}{|l|}{ Self-medication } \\
\hline No & $\begin{array}{l}108 \\
(67.92)\end{array}$ & $51(32.07)$ & $5.44(1)$ & 0.020 & 0.17 \\
\hline Yes & $36(87.80)$ & 05 (12.19) & & & \\
\hline \multicolumn{6}{|l|}{$\begin{array}{l}\text { Doctor-patient } \\
\text { communication }\end{array}$} \\
\hline Yes & $\begin{array}{l}105 \\
(82.67)\end{array}$ & $22(17.32)$ & $\begin{array}{l}18.25 \\
\text { (1) }\end{array}$ & 0.001 & 0.31 \\
\hline No & 39 (53.42) & $34(46.57)$ & & & \\
\hline \multicolumn{6}{|c|}{ Knowledge about eye drops } \\
\hline Yes & $78(85.71)$ & $13(14.28)$ & 15.57 & 0.001 & 0.27 \\
\hline No & $66(60.55)$ & $43(39.44)$ & (1) & & \\
\hline \multicolumn{6}{|c|}{$\begin{array}{l}\text { Perceived benefit of } \\
\text { treatment }\end{array}$} \\
\hline Yes & $\begin{array}{l}105 \\
(84.67)\end{array}$ & 19 (15.32) & $\begin{array}{l}24.38 \\
(1)\end{array}$ & 0.001 & 0.36 \\
\hline \multirow{2}{*}{\multicolumn{6}{|c|}{ Overall satisfaction }} \\
\hline & & & & & \\
\hline Yes & $\begin{array}{l}105 \\
(85.36)\end{array}$ & 18 (14.63) & $26.61(1)$ & 0.001 & 0.37 \\
\hline No & $39(50.64)$ & $38(52.05)$ & & & \\
\hline
\end{tabular}

Table 9: Predictors of compliance with glaucoma therapy

\begin{tabular}{|c|c|c|c|c|c|}
\hline \multirow[t]{2}{*}{ Predictors } & \multicolumn{2}{|c|}{ Compliance with glaucoma therapy } & \multirow[t]{2}{*}{$\chi 2(\mathrm{df})$} & \multirow[t]{2}{*}{ p-value } & \multirow{2}{*}{$\begin{array}{l}\text { Odd Ratio (95\% } \\
\text { CI) }\end{array}$} \\
\hline & $\begin{array}{l}\text { Compliant } \\
\text { n (\%) }\end{array}$ & $\begin{array}{l}\text { Non-compliant } \\
\text { n (\%) }\end{array}$ & & & \\
\hline \multicolumn{6}{|c|}{ Self-medication } \\
\hline No & $108(67.92)$ & $51(32.07)$ & $5.44(1)$ & 0.01 & $0.28(0.09-0.81)$ \\
\hline Yes & $36(87.80)$ & $05(12.19)$ & & & 1 \\
\hline \multicolumn{6}{|c|}{ Knowledge about eye drops } \\
\hline Yes & $78(85.71)$ & $13(14.28)$ & $15.57(1)$ & 0.58 & 1 \\
\hline No & $66(60.55)$ & $43(39.44)$ & & & $1.29(0.51-3.24)$ \\
\hline \multicolumn{6}{|c|}{$\begin{array}{l}\text { Doctor-patient } \\
\text { communication }\end{array}$} \\
\hline Yes & 105 (82.67) & $22(17.32)$ & $18.25(1)$ & 0.03 & 1 \\
\hline No & $39(53.42)$ & $34(46.57)$ & & & $2.27(1.06-4.86)$ \\
\hline \multicolumn{6}{|c|}{$\begin{array}{l}\text { Perceived benefit of } \\
\text { treatment }\end{array}$} \\
\hline Yes & $105(84.67)$ & $19(15.32)$ & $24.38(1)$ & 0.55 & 1 \\
\hline \multicolumn{6}{|c|}{ Overall satisfaction } \\
\hline Yes & $105(85.36)$ & $18(14.63)$ & $26.61(1)$ & 0.06 & 1 \\
\hline No & $39(50.64)$ & $38(52.05)$ & & & $2.87(0.92-8.96)$ \\
\hline
\end{tabular}

therapy [33]. This was followed by $35.00 \%$ in this study who reported that they find difficulty in reading the prescription due to poor visual status.

Almost $30 \%$ of the respondents were not having IOP within normal range in the current study. Thirty-one patients (15.50\%) reported that they are not visiting the hospital (follow up) on their respective appointment time followed by $19(9.50 \%)$ of them saying that they are not using all the medications. This is tragic as such negligence on the patient's side can nullify the beneficial effect of the treatment regimen and all the efforts to decrease the visual loss will go in vain as stated by Denis where medical adherence was reported to be crucial for effective glaucoma treatment [34].

A large number of patients reported stinging (15.50\%), burning $(11.00 \%)$, and itching $(10.00 \%)$ as the side effects of the long-term glaucoma therapy. This is in agreement with the study by Baloch et al. where side effects from treatment were the cause for poor adherence to glaucoma therapy [30].
Basic knowledge of patients about their disease was found to be poor as almost $20 \%$ of the patients responded that they were not familiar with their ocular condition. Almost one third (47.50\%) of the patients were confused whether glaucoma medications could completely end their disease followed by only 14 patients who were certain that their disease could not be ended up completely by glaucoma medications. Knowledge about eye drops was found out to be statistically significant with compliance level $(\mathrm{p}<0.050)$ in the current study.

Living with chronic diseases is a challenge in its self without enough family support. This was assessed in the current study by proxy indication of the presence of attendant with the patient in the hospital where more than half of the patients (58.50\%) were alone indicating that the family members take the disease and regular follow-ups of the patient for granted and/or as part of the routine, or it may be because they have jobs and could not make days off for every follow-up. They do not pose importance to patient's restrictive visual field and utmost need of the guide in patient's orientation and mobility. A Korean study by Yoo et al. showed statistically significant association of family support with glaucoma medication compliance [35]. 
This study was one of its kind in finding out adherence to glaucoma treatment. It has not only relied on the patient's response for checking the level of non-compliance but also has taken the readings of IOP to correlate the patient's response. The limitations of the study were that the detailed factors for non-compliance or the underlying factors for shift in IOP could not be reached out because of shortage of time. Moreover, this study was performed only in hospital setting which could have masked few facts like observing the presence and proper use of prescribed medication. More glaucoma centers should be made to reduce patient burden and increase the patientdoctor sitting time. Large-scale studies are required to figure out the reasons for noncompliance and overcoming those to beat this avoidable silent killer of vision (Glaucoma), thus ensuring efficient use of Healthcare resources for the betterment of Public Good.

\section{CONCLUSION}

Almost $30 \%$ of the respondents showed non-adherence to glaucoma therapy. Knowledge of the disease and lack of satisfaction with treatment were significant factors. However, poor communication with the doctor and self-medication were predictors of non-compliance.

\section{REFERENCES}

1. Bathija R, Gupta N, Zangwill L, Weinreb R. Changing definition of glaucoma. J Glaucoma 1998; 7:165-9.

2. Tham Y, Li X, Wong T, Quigley H, Aung T, Cheng C. Global prevalence of glaucoma and projections of glaucoma burden through 2040. Ophthalmology 2014;121:2081-90.

3. World Health Organization. The Global Impact of Glaucoma. Geneva: World Health Organization; 2020. Available from: https://www.who.int/ blindness/publications/glaucoma/en [Last accessed on 2020 Oct 12].

4. Quigley $\mathrm{H}$. The number of people with glaucoma worldwide in 2010 and 2020. Br J Ophthalmol 2006;90:262-7.

5. Chan E, Li X, Tham Y, Liao J, Wong T, Aung T, et al. Glaucoma in Asia: Regional prevalence variations and future projections. Br J Ophthalmol 2015; 100:78-85.

6. Half of $1.8 \mathrm{mn}$ Glaucoma Patients in Pakistan Already Blind; 2020. Available from: https://www.dawn.com/news/612360 [Last accessed on 2020 April 19].

7. Available from: https://www.collinsdictionary.com/dictionary/english/ compliance

8. Informed Health. Treatment Options for Glaucoma. Cologne, Germany: Institute for Quality and Efficiency in Health Care (IQWiG); 2012.

9. Tsai JC, McClure CA, Ramos SE, Schlundt DG, Pichert JW. Compliance barriers in glaucoma: A systematic classification. J Glaucoma 2003;12:393-8.

10. Kosoko O, Quigley H, Vitale S, Enger C, Kerrigan L, Tielsch J. Risk factors for noncompliance with glaucoma follow-up visits in a residents' eye clinic. Ophthalmology 1998;105:2105-11.

11. Abu Hussein N, Eissa I, Abdel-Kader A. Analysis of factors affecting patients' compliance to topical antiglaucoma medications in Egypt as a developing country model. J Ophthalmol 2015;2015:1-7.

12. Khan H, Mahsood Y, Gul N, Ilyas O, Jan S. Factors responsible for noncompliance of glaucoma patients to topical medications in our setup. Pak J Ophthalmol 2018;34:265.

13. Dreer L, Girkin C, Mansberger S. Determinants of medication adherence to topical glaucoma therapy. J Glaucoma 2012;21:234-40.

14. Taylor SA, Galbraith SM, Mills RP. Causes of non-compliance with drug regimens in glaucoma patients: A qualitative study. J Ocul Pharmacol Ther 2002;18:401-9.

15. Nordmann JP, Auzanneau N, Ricard S, Berdeaux G. Vision related quality of life and topical glaucoma treatment side effects. Health Qual Life Outcomes 2003;1:75

16. Nayak NV, Lin J, Forster S, Tsai JC. Assessment of barriers to medication adherence and follow-up exams in glaucoma patients. Invest Ophthalmol Vis Sci 2012;53:4485.

17. Clewley D, Rhon D, Flynn T, Koppenhaver S, Cook C. Health seeking behavior as a predictor of healthcare utilization in a population of patients with spinal pain. PLoS One 2018;13:e0201348.

18. Al-Shifa Trust Eye Hospital Pakistan; 2020. Available from: https:// www.alshifaeye.org [Last accessed on 2020 Oct 08].

19. OpenEpi Menu; 2020. Available from: https://www.openepi.com/ menu/oe menu.htm [Last accessed on 2020 Oct 12].

20. Castro A N, Mesquita WA. Noncompliance with drug therapy of glaucoma: A review about intervening factors. Braz J Pharm Sci 2009;45:453-9.

21. Robin AL, Covert D. Does adjunctive glaucoma therapy affect adherence to the initial primary therapy? Ophthalmology 2005;112:863-8.

22. Muir K, Santiago-Turla C, Stinnett S, Herndon L, Allingham R, Challa P, et al. Health literacy and adherence to glaucoma therapy. Am J Ophthalmol 2006;142:223-6.e2.

23. Jahan F, Siddiqui H. Good communication between doctor-patient improves health outcome. Eur J Med Health Sci 2019;1. Doi: https:// doi.org/10.24018/ejmed.2019.1.4.84.

24. Hussain S, Malik F, Hameed A, Ahmed S, Riaz H, Abbasi N, et al. Pakistani pharmacy students' perception about complementary and alternative medicine. Am J Pharm Educ 2012;76:21.

25. Doctor/Patient Relationship Key to Glaucoma Therapy Compliance; 2021. Available from: https://www.healio.com/news/ optometry/20120225/doctor-patient-relationship-key-to-glaucomatherapy-compliance [Last accessed on $2020 \mathrm{Apr} 02$ ].

26. Byrne J. Doctor/Patient Relationship Key to Glaucoma Therapy Compliance; 2020. Available from: https://www.healio.com/optometry/ glaucoma/news/print/primary-care-optometry-news/\%7bdaf332ceb296-47aa-8b78-d1bebba169f2\%7d/doctorpatient-relationship-key-toglaucoma-therapy-compliance [Last accessed on $2020 \mathrm{Apr} 19$ ]

27. Taylor S, Galbraith S, Mills R. Causes of non-compliance with drug regimens in glaucoma patients: A qualitative study. J Ocul Pharmacol Ther 2002;18:401-9.

28. Granstrom P. Glaucoma patients not compliant with their drug therapy: Clinical and behavioural aspects. Br J Ophthalmol 1982;66:464-70

29. Silva L, de Paula J, Rocha E, Rodrigues M. Factors related to glaucoma treatment compliance: Patients' opinions from a University Hospital. Arq Bras Oftalmol 2010;73:116-9.

30. Bloch S, Rosenthal A, Friedman L, Caldarolla P. Patient compliance in glaucoma. Br J Ophthalmol 1977;61:531-4.

31. Abdujawad KW, Alhussain E, Ahmad AM, Madani FM, Bakkar SA, Abduljawad KW. Compliance of glaucoma patients to their medical treatment in Jeddah. Int J Med Res Prof 2018;4:410-9.

32. de Castro AN, Mesquita WA. Noncompliance with drug therapy of glaucoma: A review about intervening factors. Braz J Pharm Sci 2009;45:453-9.

33. Cook P, Schmiege S, Mansberger S, Kammer J, Fitzgerald T, Kahook M. Predictors of adherence to glaucoma treatment in a multisite study. Ann Behav Med 2014;4929-39.

34. Denis P. Adverse effects, adherence and cost-benefits in glaucoma treatment. Eur Ophthalmic Rev 2011;5:116.

35. Yoo S, Hwang Y. Assessment of glaucoma medication compliance. J Korean Ophthalmol Soc 2015;56:365-70. 